\title{
PD98059 enhances C2 myoblast differentiation through p38 MAPK activation: a novel role for PD98059
}

\author{
Nasser Al-Shanti and Claire E Stewart \\ Institute for Biomedical Research into Human Movement and Health, Manchester Metropolitan University, Hassall Road, Alsager, Cheshire ST7 2HL, \\ England, UK \\ (Correspondence should be addressed to N Al-Shanti; Email: n.al-shanti@mmu.ac.uk)
}

\begin{abstract}
Cell differentiation is usually accompanied by irreversible cell cycle exit, which is a critical step for skeletal muscle differentiation. We therefore hypothesise that PD98059 that blocks the MAP kinase kinase (MEK) pathway (proliferation pathway) when administrated to murine C2 skeletal myoblasts will arrest cell cycle and, consequently, enhances differentiation relative to untreated controls. In this study, we aimed to examine this hypothesis using phenotypic differentiation, biochemical assays, flow cytometry and real-time PCR in C2 cells cultured for $48 \mathrm{~h}$ in differentiation media only (untreated) or supplemented with either a single dose of $10 \mathrm{ng} / \mathrm{ml}$ IGF-I or $20 \mu \mathrm{M}$ PD98059 for $48 \mathrm{~h}$. Creatine kinase (CK) activity was increased by $7 \cdot 5$-fold $(P<0 \cdot 05)$ in the presence of PD98059, whereas untreated and IGF-I-treated cells induced 4.5- and 4-fold increase respectively when compared with baseline controls. Increased CK values in the presence of PD98059 were not only associated with myotube formation but also associated with cell cycle arrest in G1 phase $(86 \pm 3 \cdot 2 \% ; P<0 \cdot 05)$. Moreover, the expression of myogenic-specific transcriptional factor mRNAs (MyoD and myogenin) was significantly higher in
\end{abstract}

PD-treated cells $(4 \cdot 7 \pm 0 \cdot 15$ and $314 \pm 10 \cdot 2 \mathrm{ng} /$ reaction respectively; $P<0 \cdot 05)$ than untreated $(2 \cdot 0 \pm 0 \cdot 2$ and $233 \pm 11 \mathrm{ng} /$ reaction respectively) or IGF-treated cells $(3 \cdot 2 \pm 0 \cdot 24$ and $296 \pm 16 \cdot 2 \mathrm{ng} /$ reaction respectively). Unexpectedly, Id 3 mRNA, the potent negative regulator of muscle differentiation, was also expressed at significantly higher levels in PD-treated cells $(77 \pm 0 \cdot 346 \mathrm{ng} /$ reaction; $P<0 \cdot 05)$ than untreated $(49 \pm 7 \cdot 7 \mathrm{ng} /$ reaction) or IGF-I-treated cells ( $47 \pm 0 \cdot 7 \mathrm{ng} /$ reaction). Furthermore, expression of the muscle differentiation-specific genes (IGF-binding protein-5, IGF-II receptor and IGF-II) was also increased significantly in PD-treated cells when compared with untreated cells. Phosflow analysis showed a significant increase in the levels of phosphorylation of p38 mitogen-activated protein kinase $(49 \cdot 0 \pm 6 \cdot 7 \%, P<0 \cdot 05)$ in PD-treated cells when compared with DM-treated cells $(31 \cdot 7 \pm 5 \cdot 7 \%)$. These findings uncover a previously unconsidered positive effect of PD98059 on C2 myoblast differentiation and identify the pathway(s) underlying PD-induced C2 myoblast differentiation.

Journal of Endocrinology (2008) 198, 243-252

\section{Introduction}

Skeletal muscle is derived from pluripotent mesodermal stem cells through a multistep process including the commitment to myogenic precursors and their subsequent proliferation and differentiation (Rawls \& Olson 1997). Skeletal muscle differentiation is a highly ordered process and elucidates the temporal relationships among the events that govern the transition from the proliferation to the terminally differentiated myoblast. These events are 1) entry of myoblasts into the differentiation pathway and activation of muscle-specific genes (muscle contractile protein) by myogenic proteins, 2) irreversible cell cycle exit (indicated by expression of p21), 3) phenotypic differentiation and 4) myoblast fusion resulting in myotube formation (Buckingham 1992, Edmondson \& Olson 1993, Weintraub 1993, Andres \& Walsh 1996). In addition, skeletal muscle differentiation requires several growth factors, such as insulin-like growth factor-I (IGF-I),
IGF-II, hepatocyte growth factor and basic fibroblast growth factor, that mediate their biological effects through various intracellular signalling cascades, such as Janus kinase/signal transducers and activators of transcription, Ras/mitogenactivated protein kinase (MAPK) and phosphatidylinositol 3-kinase (Coolican et al. 1997, Rommel et al. 1999, Wu et al. 2000). The extracellular signal-regulated kinase (ERK) pathway is the cascade most often associated with signalling mechanisms involved in cell proliferation and cell cycle progression but more recently also in apoptosis (Johnson \& Lapadat 2002). A potent method to determine the biological effects of cellular signalling pathways is to use selective inhibitors to block specific pathways. Generally, protein kinase inhibitors are competitive with ATP and are believed to interact within ATP-binding sites of their target protein kinases, which makes these inhibitors less specific (Davies et al. 2000). By contrast, PD 98059 agent blocks ERK activity by inhibiting activation (phosphorylation) of MEK by Raf-1, 
conferring some specificity to PD98059 (Alessi et al. 1995). Since cell cycle arrest is a critical step for skeletal muscle differentiation and PD98059 induces G1 cell cycle arrest in many cell types (Hoshino et al. 2001, Moon et al. 2007), we therefore hypothesise that administration of PD98059 to C2 skeletal myoblast cultures may enhance cell differentiation relative to controls. The purpose of the present study described herein was to examine a potential positive role for PD98059 in myoblast differentiation. The results from this study demonstrate that PD98059 induces increased cell differentiation compared with IGF-I, a potent myogenic factor (Florini et al. 1996), in untreated cells. This novel finding was confirmed by increased creatine kinase (CK) activity and morphological differentiation, which was indicated by myotube formation. We have also examined the effect of PD98059 not only on the expression levels of myogenic transcriptional factor mRNAs (myogenin and MyoD) but also on mRNAs for IGF system components, which are vital for $\mathrm{C} 2$ differentiation. These mRNAs include IGF-II, IGF-II receptor (IGF-IIR), IGF-binding protein-5 (IGFBP-5) and IGF-IR. Furthermore, the involvement of p38 MAPK in these settings was also investigated. These interesting data begin to examine and address the molecular mechanisms by which PD98059 enhances myoblast differentiation and the signalling pathways involved in this process.

\section{Materials and Methods}

\section{Materials}

All chemicals and reagents, unless otherwise stated, were purchased from Sigma. All cell and tissue culture media and supplements were purchased as sterile or were filter sterilised through a $0 \cdot 20 \mu \mathrm{m}$ filter. Heat-inactivated (hi) fetal bovine serum (FBS) and hi new born calf serum (NCS) were purchased from Gibco, hi horse serum (HS) was from TCS Biosciences (Corby, England), Penstrep (penicillin and streptomycin) and trypsin from Bio Whittaker (Wokingham, England), L-glutamine from BDH (Poole, England) and gelatine and phorbol-12-myristate-13-acetate (PMA) from Sigma. Recombinant human IGF-I was obtained from GroPep (Adelaide, Australia), PD98059 and SB202190 inhibitor - dimethyl sulphoxide (DMSO) dissolved - were purchased form Calbiochem (Nottingham, UK) and CK assay kits from Catachem (Bridgeport, CT, USA). Phosflow reagents, anti-phospho-ERK1/2 (T202/Y204) PE-conjugated anti-phospho-p38 MAPK (T180/Y182), PE-conjugated BD Phosflow fix buffer and BD Phosflow Perm Buffer III were ordered from Becton Dickinson (BD, Oxford, UK).

\section{Cell culture}

C2 mouse skeletal myoblasts (Yaffe \& Saxel 1977) were grown in a humidified $5 \% \mathrm{CO}_{2}$ atmosphere at $37^{\circ} \mathrm{C}$ in a growth medium (GM) composed of Dulbecco's modified Engle's meduimn
(DMEM) with GlutaMAX supplemented with 10\% FBS, 10\% NCS, penstrep and L-glutamine, at final concentrations of $10000 \mathrm{U} / \mathrm{ml}$ and $2 \mathrm{mM}$ respectively, until $80 \%$ confluence was attained. Experiments and differentiation were initiated following washing with PBS, by transferring to low serumcontaining differentiation medium (DM; DMEM plus GlutaMAX, supplemented with $2 \%$ HS, penstrep and L-glutamine (supplemented as above)) in the presence or absence of specific triggers. These cells are able to undergo spontaneous differentiation into myotubes on serum withdrawal and do not require growth factor addition to stimulate the process.

\section{Cell treatments}

Six-well plates were pre-coated with $0 \cdot 2 \%$ gelatine for $5 \mathrm{~min}$ at $\mathrm{RT}$ and the cells were plated at a density of $1 \times 10^{5}$ cells $/ \mathrm{ml}$ in the GM to attain confluence the following day. Then the cells were washed twice with PBS and DM was added to the cells that were incubated for $30 \mathrm{~min}$ at $37^{\circ} \mathrm{C}$ (this time point was denoted time $0, T_{0}$ ) prior to further treatments for up to $48 \mathrm{~h}$. The cells were cultured for $48 \mathrm{~h}$ in DM only (untreated) or DM supplemented either with $10 \mathrm{ng} / \mathrm{ml}$ IGF-I (potent myogenic factor) or with $20 \mu \mathrm{M}$ PD98059. The concentrations of PD98059 and IGF-I, which were used in the present study, were optimised by our group previously (Stewart et al. 2004).

\section{CK assay}

After $48 \mathrm{~h}$ with different treatments, cells were lysed in $200 \mu \mathrm{l}$ TMT buffer (50 mM Tris-MES (pH 7•8), 1\% Triton X-100), and $\mathrm{CK}$ was measured using a commercially available kit (Catachem). Absorbance was measured at 3, 4 and $5 \mathrm{~min}$ at $340 \mathrm{~nm}$ and changes in absorbance/minute and CK activity were then calculated and normalised to total protein concentration as determined by BCA protein assay, according to the manufacturer's instruction.

\section{Phenotypic differentiation}

Morphological parameters of differentiation, alignment, elongation and fusion were assessed by cell imaging system at $20 \times$ magnification at $48 \mathrm{~h}$ (Leica Microsystems, Milton Keynes, UK, DMI 6000 B).

\section{Phosflow analysis of ERK and $p 38$ protein phosphorylation levels}

Phosphospecific flow cytometry, which is a powerful tool to analyse and measure the levels of intracellular phosphoproteins (Krutzik \& Nolan 2003), was used in the present study. At the end of the cell treatments, the cells were rapidly detached using trypsin-EDTA buffer and fixed immediately by adding equal volume of pre-warmed BD Phosflow fix buffer. The cells were then incubated at $37^{\circ} \mathrm{C}$ for $15 \mathrm{~min}$ followed by washing twice with cold PBS by centrifugation at $250 \boldsymbol{g}$ for $10 \mathrm{~min}$. Immediately after washing, the cells were 
permeabilised by adding cold BD Phosflow Perm Buffer III and incubated for a minimum of $30 \mathrm{~min}$ at $-20^{\circ} \mathrm{C}$. Finally, the cells were washed twice with staining buffer in $1 \times \mathrm{PBS}$, $1 \%$ FBS and $0 \cdot 09 \%$ sodium azide for $10 \mathrm{~min}$ by centrifugation at $200 \mathrm{~g}$ and resuspended in staining buffer at a concentration of $1 \times 10^{6}$ cells $/ \mathrm{ml}$. To each tube were added $20 \mu \mathrm{l}$ antiphospho-ERK1/2 and anti-p38 antibody. The cells were then subjected to Phosflow analysis using FACSCalibur (BD). Percentage of positive cells for phosphorylated ERK protein was calculated by dividing the median fluorescence intensity (MFI) of each sample by MFI of PMA-treated cells $\times 100 \%$.

\section{DNA content and cell cycle analysis}

After 48-h incubation under the conditions described previously, cells were harvested using trypsin-EDTA buffer. The cells were washed twice with PBS by centrifugation at $200 \boldsymbol{g}$ for $10 \mathrm{~min}$. The pellets obtained were resuspended in $5 \mathrm{ml}$ of $75 \%$ ethanol. After overnight incubation at $-20{ }^{\circ} \mathrm{C}$, the cells were washed twice with ice-cold PBS by centrifugation at $200 \mathrm{~g}$ for $10 \mathrm{~min}$, and then resuspended in $0.5 \mathrm{ml}$ PBS followed by the addition of $10 \mu \mathrm{l}$ propidium iodide $(50 \mu \mathrm{g} / \mathrm{ml})$ and $50 \mu \mathrm{l}$ RNase $(60 \mu \mathrm{g} / \mathrm{ml})$. Following overnight incubation at $4{ }^{\circ} \mathrm{C}$, DNA content was measured on FACSCalibur flow cytometer (BD) and analysed using Cell Quest (BD) and Flowjo software packages.

\section{Primer design and synthesis}

Optimal primer designs are essential to ensure that only a single PCR product is amplified in particular in real-time PCR-based SYBR Green. We therefore used web-based software from Invitrogen to design our primers (Table 1) that were further analysed by Sigma-Genosys software. The primers were designed to yield products spanning exonintron boundaries to prevent any possible genomic DNA contamination from total RNA isolation. Sequence homology searches against the database of GenBank showed that these primers matched only the sequence to which they were designed. The primers were synthesised by SigmaGenosys, which are compatible with real-time PCR without further purification.

\section{Quantitative real-time PCR and data analysis}

RNA was extracted using the TRIzol method, according to the manufacturer's instructions (Invitrogen) and $30 \mathrm{ng}$ RNA was used per reaction. Real-time PCR amplifications were carried out using SYBR Green One-Step qRT-PCR and Chromo4, according to the manufacturer's instructions (BioRad). In brief, real-time PCR was performed by the following cycles: $50{ }^{\circ} \mathrm{C}$ for $10 \mathrm{~min}$ (for cDNA synthesis), $95^{\circ} \mathrm{C}$ for $5 \mathrm{~min}$ (transcriptase inactivation), followed by the cycling parameters of $95^{\circ} \mathrm{C}$ for $10 \mathrm{~s}$ and $60^{\circ} \mathrm{C}$ for $30 \mathrm{~s}$ for 40 cycles. At the end of the 40 cycles, dissociation curve (melting curve) analyses were performed by the following protocol: heat at $55^{\circ} \mathrm{C}$ for $1 \mathrm{sec}$ and measure fluorescence every $0.5^{\circ} \mathrm{C}$ until $95^{\circ} \mathrm{C}$ to confirm specific amplification. Standard curve was generated by a fivefold serial dilution from total RNA at a concentration $500 \mathrm{ng}$ to $5 \mathrm{pg}$ to amplify the housekeeping gene RNA polymerase II $\alpha$ (RPII $\alpha)$. To confirm that changes in the genes of interest following the different culturing time points and treatments are not due to RNA quality or quantity, RPII $\alpha$ was amplified in all samples at each time point (Radonic et al. 2004). The Bio-Rad MJ Opticon Monitor software version 3.1 was used to analyse the data of the realtime PCR. Using the data from samples designated as standard points with assigned concentration numbers, an arbitrary threshold level is set and $C_{\mathrm{t}}$ values for all PCR samples are calculated, allowing generation of a standard curve by which the concentrations of all unknown samples were derived and averaged among replicates.

Table 1 Real-time PCR primer sequences

Primer sequence $\left(5^{\prime}-3^{\prime}\right)$

$\begin{array}{ll}\text { Target gene } & \\ \text { IGF-II } & \text { F: TCTCATCTCTTTGGCCTTCG } \\ \text { IGF-IR } & \text { F: AAGCAGCACTCTTCCACGAT } \\ & \text { F: CTACCTCCCTCTCTGGGAATG } \\ \text { IGF-IIR } & \text { F: GCCCAACCTGCTGTTATTCT } \\ & \text { R: CAGAATCGTTGAGTGGATTATG } \\ \text { IGFBP-5 } & \text { F: GACCCAGTCCAAGTTTGTGG } \\ & \text { R: GAATCCTTTGCGGTCAAGT } \\ \text { MyoD } & \text { F: CTACGACACCGCCTACTAC } \\ \text { Myogenin } & \text { R: GGCTGTCTGTGGAGATGC } \\ \text { Id3 } & \text { F: TGATTGCAACTCCCACAGC } \\ & \text { F: AGCACCGTGATGCTGTCC } \\ & \text { R: TCCTCTTGTCCTTGGAGATCAC }\end{array}$

Ref. seq. number

$\begin{array}{lc}\text { NM_010514 } & 130 \\ \text { NM_010513 } & 150 \\ \text { NM_010515 } & 95 \\ \text { NM_010518 } & 121 \\ \text { NM_010866 } & 116 \\ \text { NM_031189 } & 153 \\ \text { NM_008321 } & 135\end{array}$

Amplicon length (bp)

130

50

5

121

16

53

35

Total RNA was extracted from T0 cells and from untreated, IGF-I- and DP-treated myoblast cell for $48 \mathrm{~h}$; 30 ng RNA from each sample were used in real-time PCR. 


\section{Statistical analysis}

Statistical analysis and the significance of the data were determined using SPSS software version 12.0. Statistical significance was determined using one-way ANOVA with multiple post hoc analyses. Results are presented as mean \pm s.D. and are considered statistically significant when $P<0 \cdot 05$ against appropriate controls.

\section{Results}

PD98059 blocks phosphorylation of phospho-ERK protein

The main purpose of the present study is to examine a possible role that PD98059 may play in myoblast differentiation. Since PD98059 is dissolved in DMSO, primary experiments were initiated comparing DM-treated with DM-DMSO-treated cells to rule out any possible effect of DMSO on myoblast differentiation. The data from all the experiments were comparable between the two treatments and confirm that DMSO has no effect on myoblast differentiation (data not shown).

As an essential first step towards evaluating a potential role of PD98059 in myoblast differentiation, we analysed the phosphorylation events of ERK protein in the different cell treatments using phosphoprotein flow cytometry to confirm the blockade of the ERK pathway. To validate the methodology of phosphoprotein flow cytometry, stimulation with PMA, which induces strong phosphorylation of ERK, was included as a positive control. In this experiment, IGF-I, which is a unique potent mitogenic and myogenic factor, was also included (Florini et al. 1996). We found that myoblasts under basal or IGF-stimulated conditions were $77 \pm 8.6$ and $69 \pm 7 \%$ positive for phosphorylated ERK protein respectively (Fig. 1A and B), whereas the cells stimulated with PMA for 10 min were $92 \pm$ $2 \cdot 5 \%$ positive for phosphorylated ERK protein (Fig. 1C). However, PD-treated cells showed insignificant phosphorylation of ERK protein $(2 \cdot 3 \pm 0 \cdot 6 \%$, Fig. 1D), which indicates that the ERK pathway was effectively blocked.

\section{PD98059 induces CK activity and morphological differentiation}

Morphological and biochemical studies were performed to examine our hypothesis that PD98059 may induce C2 cell differentiation. DM and IGF-I were included in this study as positive controls for promoting cell differentiation. Photomicrographs were taken prior to harvesting the cells at $48 \mathrm{~h}$ for CK assay. CK activity increased significantly $(P<0 \cdot 05)$ and variably by $4-, 4 \cdot 5-$ and $7 \cdot 5$-fold in the presence of DM, IGF-I and PD98059 respectively, when compared with baseline levels of $T_{0}$ control cells (Fig. 2A). Furthermore, when PD98059 treatment was compared with DM at 48 h, PD98059 elicited a significant $(P<0.05)$ twofold increase in CK activity. These biochemical findings were supported morphologically whereby the most prominent differentiation and myotube formation are evident in the PD-treated cultures at 48 h (Fig. 2B).
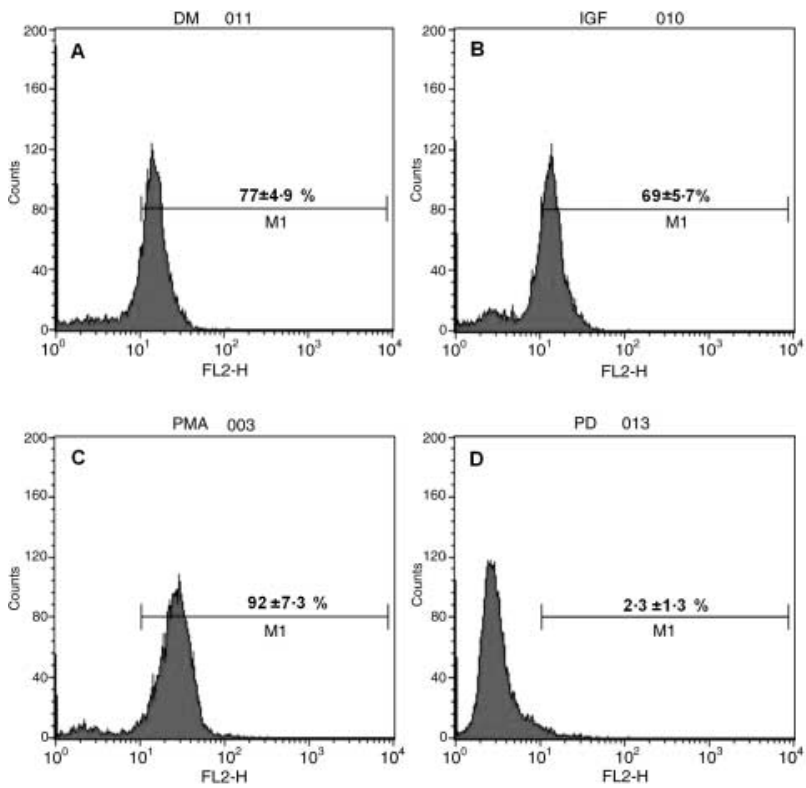

Figure 1 Phosflow analysis of ERK protein phosphorylation levels. C2 myoblasts were cultured in (A) DM only or (B) DM supplemented with either $10 \mathrm{ng} / \mathrm{ml}$ IGF-I or (D) $20 \mu \mathrm{M}$ PD98059 for $48 \mathrm{~h}$. (C) PMA-treated cells $(40 \mathrm{nM})$ for $10 \mathrm{~min}$ were used as positive stimuli that produces strong induction ERK protein phosphorylation. At the end of the cell treatments, the cells were detached using trypsin, and immediately fixed in BD Phosflow fix buffer and permeabilised by BD Phosflow Perm Buffer III. The cell pellets were stained with anti-phospho-ERK1/2 and subjected to flow cytometry analysis. Percentage of positive cells for phosphorylated ERK protein was calculated by dividing the MFI of each sample by MFI of PMA-treated cells $\times 100 \%$. These data present the mean \pm s.D. of the treatments performed four times.

PD98059 does not enhance DM-induced cell cycle arrest at $48 \mathrm{~h}$

G1 cell cycle arrest is a critical step for skeletal muscle cell differentiation; to investigate whether PD98059 arrested the cell cycle in G1 phase to promote cell differentiation, flow cytometry was used. $T_{0}$ cells were included in this experiment as a control for highly proliferative cells. Myoblasts at $T_{0}$ show a typical cell cycle of highly proliferative cells with $53 \%( \pm 5.9 \%)$ in G1 and $44 \%$ ( $\pm 7 \cdot 4 \%$, Fig. $3 \mathrm{~A})$ in S-G2/M phase. However, when the cells were cultured for $48 \mathrm{~h}$ with DM or IGF-I (differentiation conditions), the proportion of proliferating cells in S-G2/M phases decreased in both cultures to $11 \pm 2 \cdot 9 \%$ (Fig. 3B) and $16 \pm 1 \cdot 69 \%$ (Fig. 3C) respectively. Similarly, PD-treated cells showed a typical cell cycle phase of differentiating cells where the majority of the cells were arrested in G1 $(86 \pm 3 \cdot 2 \%)$ with only small numbers present in S-G2/M (12.5 $\pm 3 \cdot 4 \%$ (Fig. 3D)).

\section{PD98059 activates transcription of myogenic regulatory factors}

Myogenic regulatory factors (MRFs) (myogenin and MyoD) are known to control myoblast differentiation (Molkentin \& Olson 1996, Venuti \& Cserjesi 1996); therefore to examine 


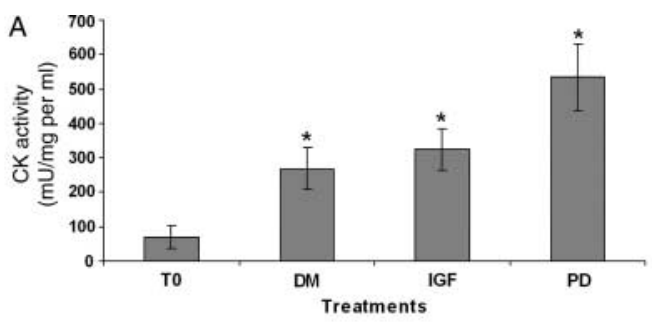

B
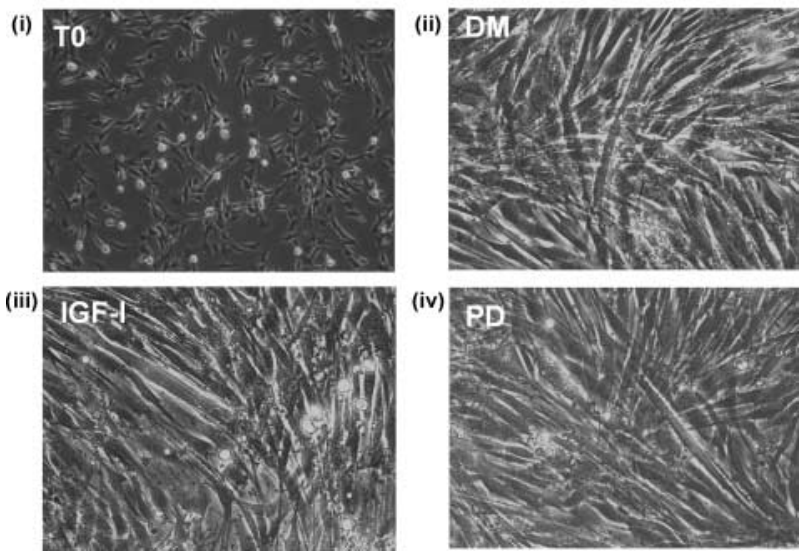

Figure 2 Biochemical and morphological effects of PD98059 on C2 myoblasts. C2 myoblasts were cultured with DM only or DM supplemented with either $10 \mathrm{ng} / \mathrm{ml} \mathrm{IGF-I} \mathrm{or} 20 \mu \mathrm{M}$ PD98059. At the end of the cell treatments $(48 \mathrm{~h})$, the cells were subjected either to (A) $\mathrm{CK}$ assay or to morphological studies to observe myoblast fusion and myotube formation in (BI) T0 control, (BII) DM-, (BIII) IGF- and (BIV) DP-treated cells. T0 was also included as control for highly proliferating cells. Calculated CK activity was normalised to total protein concentration as determined by BCA protein assay. CK data present the mean \pm s.D. of the treatments performed four times. $* P<0 \cdot 05$ versus T0. (B) Representative photomicrograph of random fields from four independent experiments.

whether PD98059 upregulates the transcription of these factors to enhance cell differentiation, real-time PCR was performed. Our real-time PCR data were validated using individual standard curve that showed correlation coefficients of $\sim 1 \cdot 0(0 \cdot 990)$ and the melting (dissociation) curves of these data exhibit a sharp clean peak. This result indicates that the products are specific, and that SYBR Green I fluorescence is a direct measure of accumulation of the product of interest (data not shown).

The expression levels of the control housekeeping gene (mRNA RPII $\alpha$ ) in all treatment groups was between 6-8 \pm $0 \cdot 05 \mathrm{ng} /$ reaction $(P=\mathrm{NS}$; data not shown). Real-time PCR further showed that treatment of myoblasts with IGF-I for $48 \mathrm{~h}$ elicited $60 \pm 21 \%$ increase in MyoD and $19 \pm 9 \%$ increase in myogenin expression, compared with untreated controls (Fig. 4). PD98059 led to a significant increase in MyoD ( $4 \cdot 7 \pm 0 \cdot 2 \mathrm{ng} /$ reaction, $P<0 \cdot 05$; Fig. 4 , white bars $)$ and myogenin $(314 \pm 10 \cdot 2 \mathrm{ng} /$ reaction, $P<0 \cdot 05$; Fig. 4 , grey bars) mRNA levels compared with $T_{0}$ control cells $(2 \cdot 0 \pm 0 \cdot 2$ and $233 \pm 11.4 \mathrm{ng} /$ reaction, respectively; Fig. 4 , white and
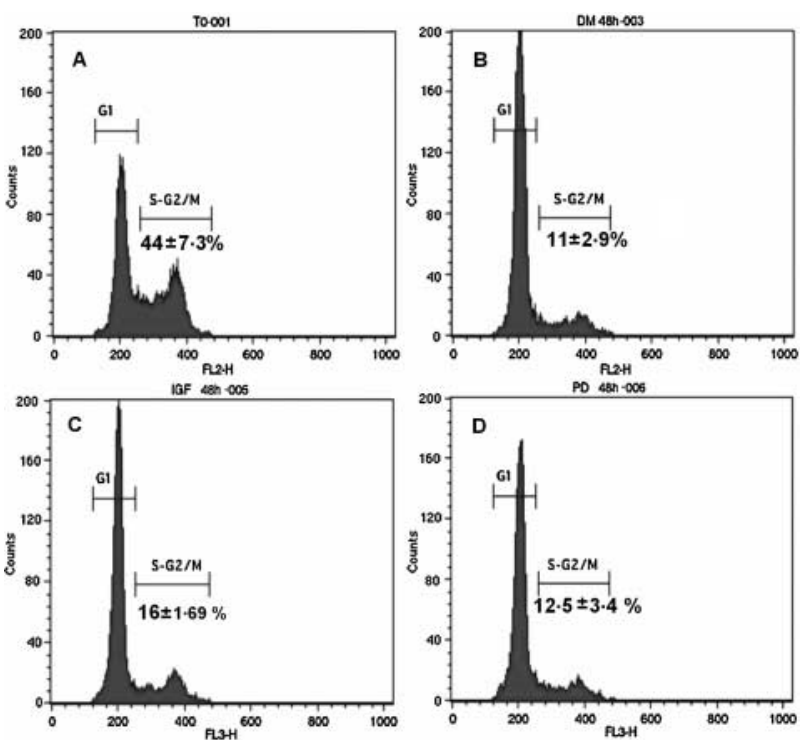

Figure 3 Effects of PD98059 on C2 myoblast cell cycle and DNA content. C2 myoblasts were cultured and prepared as detailed in Fig. 2. DNA content and cell cycle phase of (A) T0, (B) untreated, (C) IGF-I-treated and (D) PD-treated cells were examined by propidium iodide staining using flow cytometry. The proportions of cells in $\mathrm{S}-\mathrm{G} 2 / \mathrm{M}$ phase are indicated. These data present the mean \pm s.D. of the treatments performed four times.

grey bars). PD98059 still elicited significant increases in each of these mRNAs $(135 \pm 8 \%$ in MyoD and $16 \pm 7 \%$ in myogenin) when compared with DM.

Myoblast differentiation is also regulated by an inhibitor of differentiation gene 3 (Atherton et al. 1996, Arnold \& Winter 1998, Wu \& Lim 2005). We therefore tested whether PD98059 blocks the expression of Id 3 mRNA to enhance differentiation. As expected, the expression level of Id3

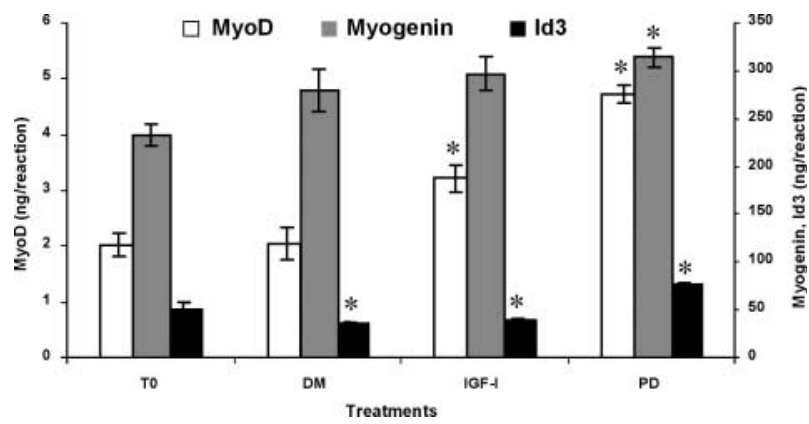

Figure 4 Absolute mRNA levels of transcriptional factors with regulatory roles in muscle differentiation. C2 myoblasts were cultured in DM only or DM supplemented with either $10 \mathrm{ng} / \mathrm{ml}$ IGF-I or $20 \mu \mathrm{M}$ PD98059 for $48 \mathrm{~h}$. T0 was also included as control for highly proliferating cells. Total RNA was extracted from cells, and $30 \mathrm{ng}$ from each sample was used to perform real-time RT-PCR. Standard curve was used to calculate the absolute concentration and expression of target genes MyoD (white bars), myogenin (grey bars) and Id 3 (black bars) based on $\Delta C_{t}$ values. These data present the mean \pm s.D. of the treatments performed three times in triplicate. $* P<0 \cdot 05$ versus T0. 
mRNA was reduced significantly $(P<0 \cdot 05)$ to $36 \pm 0.4$ and $40 \pm 0 \cdot 7 \mathrm{ng} /$ reaction in DM- and IGF-I-treated myoblasts respectively, when compared with $T_{0}(49 \cdot 8 \pm 7 \cdot 4 \mathrm{ng} /$ reaction, black bars). Unexpectedly, PD-treated myoblasts showed significantly increased levels of Id3 mRNA $(77 \pm 0.4 \mathrm{ng} /$ reaction) when compared not only with $T_{0}$ control cells but also with DM or IGF-I treatments (Fig. 4, black bars).

\section{PD98059 stimulates $m R N A$ expression of the IGF-I system}

To further explore the specificity of PD98059 in myoblast differentiation, we examined the mRNA expression profiles of the IGF system components (IGFBP-5, IGF-IIR, IGF-IR and IGF-II), known to have regulatory roles in muscle cell growth and differentiation. Once again the expression levels of the housekeeping gene RPII $\alpha$ mRNA were comparable among all treatments $(6-8 \pm 0 \cdot 3-0 \cdot 5 \mathrm{ng} /$ reaction $(P=\mathrm{NS}$; data not shown). Real-time PCR data analyses showed that all treatments (DM, IGF-I and PD) led to approximately twoand threefold increases $(P<0 \cdot 05)$ in expression levels of IGFBP-5 and IGF-IIR mRNAs respectively compared with $T_{0}$ control cells (Fig. 5, grey and white bars). There was no significant difference between DM, IGF or PD98059. Similarly, there was no significant difference in IGF-IR mRNA expression between all cell treatments including $T_{0}$ (data not shown). However, dramatic increases of five-, sixand tenfold were obtained in IGF-II mRNA expression in DM-, IGF-I- and PD-treated cells respectively, when compared with the expression levels of $T_{0}$ (Fig. 5, black bars). Furthermore, when compared with DM or IGF-I, PD98059 still elicited significant increases $(P<0 \cdot 05)$ in IGFII mRNA expression.

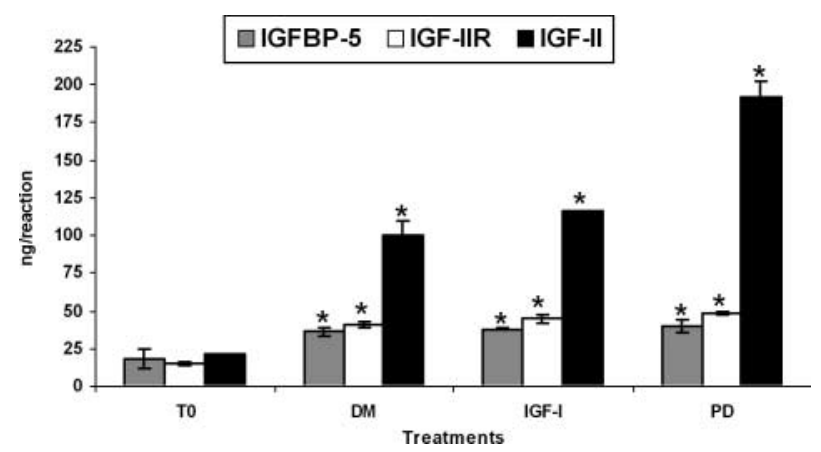

Figure 5 Absolute mRNA levels for muscle-specific genes with regulatory roles during muscle differentiation. $\mathrm{C} 2$ myoblasts were cultured in DM only or DM supplemented with either $10 \mathrm{ng} / \mathrm{ml}$ IGF-I or $20 \mu \mathrm{M}$ PD98059 for $48 \mathrm{~h}$. T0 was also included as a control for highly proliferating cells. Total RNA was extracted from cells, and $30 \mathrm{ng}$ from each sample was used to perform real-time RT-PCR. Standard curve was used to calculate the absolute concentration and expression of target genes IGFBP-5 (grey bars), IGF-IIR (white bars) and IGF-II (black bars) based on $\Delta C_{\mathrm{t}}$ values. These data present the mean \pm S.D. of the treatments performed thrice in triplicate. $* P<0 \cdot 05$ versus $\mathrm{T}_{0}$.
PD98059 induces myoblast differentiation through p38 MAPK activation

The involvement of MAPKs in osteoclast differentiation has recently been studied using specific inhibitors of MAPKERK (MEK) and p38 (Matsumoto et al. 2000, Lee et al. 2002, Wei et al. 2002). Moreover, it was reported that PD98059 may promote and accelerate osteoclast differentiation through the inhibition of ERK and activation of p38 MAP kinase pathway (Hotokezaka et al. 2002). To examine this proposed mechanism, p38 MAPK phosphorylation levels were determined in all cell treatments using anti-phospho-p38. PMA-treated and $T_{0}$ cells (unstimulated and unstained cells) were used as positive and negative controls respectively. The analysis of p38 phosphorylation by flow cytometry revealed that myoblasts under basal conditions (DM-treated cells) were $31 \cdot 7 \pm 5 \cdot 7 \%$ positive for phosphorylated p38 protein, whereas $88 \cdot 7 \pm 3 \cdot 4$ and $0 \cdot 7 \pm 0 \cdot 3 \%$ of the cells stimulated with PMA for $10 \mathrm{~min}$ and the negative control respectively were positive for phosphorylated p38 protein (Fig. 6A). Interestingly, PD-treated cells showed a significant increase in the levels of phosphorylation of $\mathrm{p} 38$ protein, by $49 \cdot 0 \pm 6 \cdot 7 \%(P<0 \cdot 05)$, when compared with basal control $(31 \cdot 7 \pm 5 \cdot 7 \%$, Fig. 6A). To ascertain whether $\mathrm{p} 38$ plays an important role in PD-induced myoblast differentiation, the cells were treated with an inhibitor to p38 MAPK (SB202190) in association with PD98059 and compared with basal control (DM-treated cells). An initial dose-response experiment $(0 \cdot 5-16 \mu \mathrm{M})$ for SB202190 was performed to ascertain an ideal working concentration; $8 \mu \mathrm{M}$ SB202190 was determined as the optimal concentration based on cell morphology, CK assay and flow cytometry data (data not shown). Morphological and biochemical studies were performed on these treatments to further confirm the involvement of p38 in our model. Photomicrographs were taken prior to harvesting the cells at $48 \mathrm{~h}$ for CK assay. CK activity decreased significantly $(P<0 \cdot 05)$ by $30 \pm 42$ and $50 \pm 9 \%$ in the presence of the combined inhibitors and p38 inhibitor respectively, when compared with baseline control levels of cells DM-treated cells (Fig. 6B). These biochemical findings were supported morphologically whereby the differentiation and myotube formation were blocked in the presence of either SB202190 or combined MEK and p38 inhibitors when compared with DM-treated cells (Fig. 6C), with the most prominent differentiation and myotube formation being evident in the PD-treated cultures at $48 \mathrm{~h}$ (Fig. 6C).

\section{Discussion}

Skeletal muscle differentiation is a highly ordered process requiring myoblast proliferation followed by cell cycle arrest, expression of muscle-specific regulatory factors and the synthesis of muscle contractile proteins, resulting in fusion of mononucleated myoblasts into terminally differentiated multinucleated myotubes (Andres \& Walsh 1996). 
The pharmacological inhibitor PD98059 has been widely utilised to infer a physiological role for MEK1/2 MAP kinase and its downstream effector MAP kinase (ERK1/2) and also routinely used to implicate ERK1/2 signalling in many different settings (Favata et al. 1998, Kultz et al. 1998, Davies et al. 2000, Galvin et al. 2003). The results presented here provide important evidence that long-term experiments (48 h) with PD98059 promote extensive myoblast differentiation and support previous data that showed PD98059 enhanced differentiation of mouse cultured primary skeletal myoblasts (Galvin et al. 2003). These studies thus uncover a

A
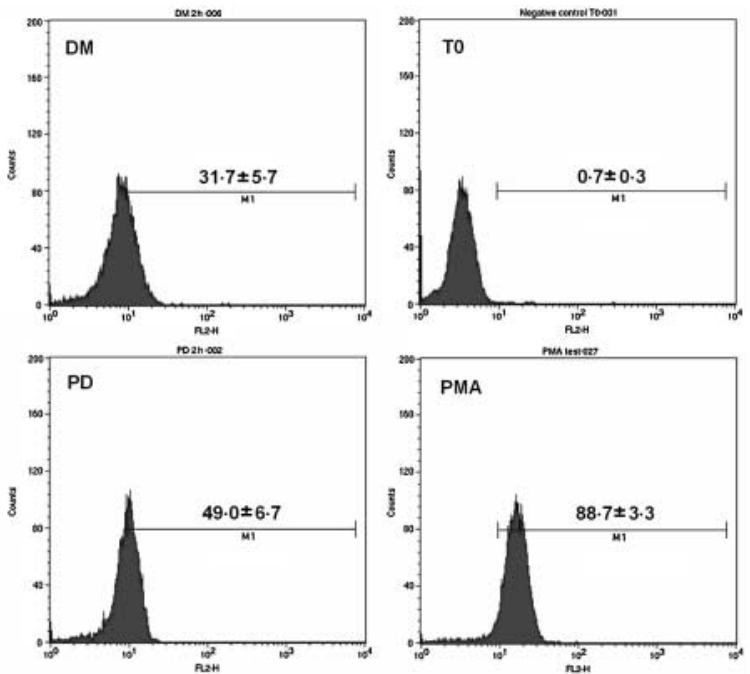

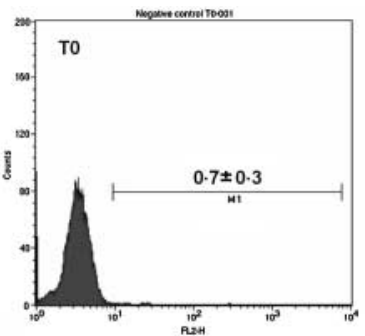

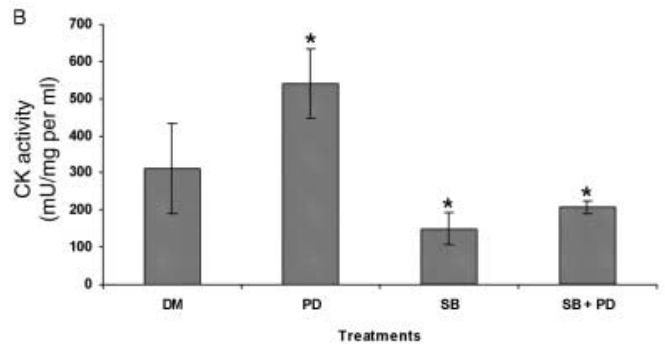

C
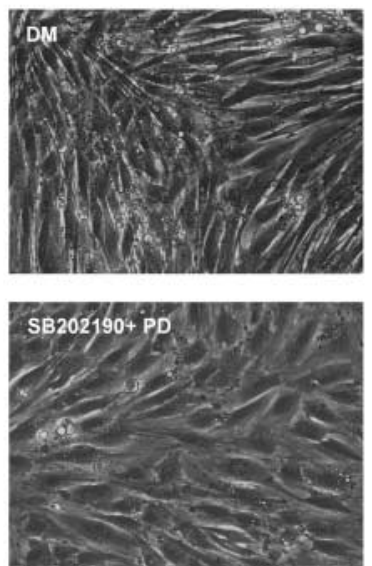

novel role of this widely used MEK inhibitor with important physiological consequences.

The effectiveness of PD98059 in blocking the ERK pathway was confirmed using phosphoprotein flow cytometry (Krutzik \& Nolan 2003) and a phosho-specific antibody against ERK1/2 protein. In association with this blockade in ERK phosphorylation and consistent with results of previous studies reporting that $\mathrm{CK}$ is strongly induced in differentiating myoblasts (Meadows et al. 2000, Foulstone et al. 2001), we also observed increased $\mathrm{CK}$ values in all treatments when compared with $T_{0}$ cells. However, the maximal CK activity was obtained in PD-treated cells, which indicates extensive cell differentiation over and above that observed with DM or IGF-I treatment. These biochemical findings support the morphological studies where myotube formation was seen in the presence of PD98059 but to a lesser extent in the presence of IGF-I at $48 \mathrm{~h}$. IGF-I is known as a unique proliferation and differentiation promoter of myoblasts (Ewton et al. 1994, Florini et al. 1996, Coolican et al. 1997, Miller et al. 2000, Singleton \& Feldman 2001). Therefore, the enhanced differentiation (both biochemical and morphological) in the presence of PD98059 versus IGF-I is potentially highly relevant when studying the regulators of enhanced myotube formation.

Recent studies have reported that PD98059 induces cell cycle arrest in G1 phase (Yamaguchi et al. 2002, Koyama et al. 2007, Moon et al. 2007, Zheng et al. 2007), which is a critical step for skeletal muscle differentiation to progress (Halevy et al. 1995, de la Serna et al. 2001). Although G1 cell cycle arrest, a prerequisite for differentiation, was comparable among treatment groups within our study, it does not define the subsequent mechanisms of actual differentiation, which could be different between treatments. This was indeed the case, as was confirmed by determining the expression levels of myogenin, MyoD, Id3 (key MRFs), IGF system components (key survival and differentiation factors) and p38 phosphorylation.

To this end, we wished to establish whether PD98059 was capable of altering the expression of the MRFs and thus increasing differentiation. We therefore investigated the effect

Figure 6 Phosflow analysis of p38 phosphorylation levels and biochemical and morphological effects of combined MEK and p38 MAPK inhibitors on C2 myoblasts. C2 myoblasts were cultured with DM only or DM supplemented with either $20 \mu \mathrm{M}$ PD98059, $8 \mu \mathrm{M}$ SB202190 or $20 \mu \mathrm{M}$ PD98059/8 $\mu \mathrm{M}$ SB202190 (combined inhibitors). At the end of the cell treatments $(48 \mathrm{~h})$, the cells were subjected either to (A) Phosflow analysis, (B) CK assay and (C) morphological studies. Phosflow analysis of $\mathrm{p} 38$ protein phosphorylation was carried out as described in Fig. 1, and the proportions of positive cells for phosphorylated p38 are indicated in histographs. The CK assay and the morphological studies to observe myoblast fusion was performed as described in Fig. 2. p38 protein phosphorylation data present the mean \pm s.D. of the treatments performed four times. ${ }^{*} P<0 \cdot 05$ versus DM-treated cells. Representative photomicrograph of random fields from four independent experiments, $C K$ data present the mean \pm s.D. of the treatments performed four times. ${ }^{*} P<0 \cdot 05$ versus DM. 
of PD98059 on the expression levels of muscle-specific transcription markers, myogenin and MyoD (Isobe et al. 1998, de la Serna et al. 2001, Zhu et al. 2007), as well as the negative regulator of differentiation, Id3 ((Wu \& Lim 2005). Myogenin and MyoD expression levels were increased, but were not significantly increased in the presence of IGF-I when compared with baseline levels. By contrast, the expression levels of their mRNA were significantly increased in the presence of PD98059 suggesting a link between PD98059, MEK, MRFs and C2 cell differentiation.

Under conditions of differentiation, one would expect a decline in Id 3 expression. Indeed, as expected, the expression of Id3 mRNA in DM-treated cells and in the presence of IGF-I was reduced significantly. In contrast to untreated and IGF-I-treated cells, PD-treated cells significantly upregulated the expression levels of Id 3 mRNA, which is controversial relative to what has been reported in C2C12 cells (Atherton et al. 1996, Melnikova \& Christy 1996, Wu \& Lim 2005). Extensive cell differentiation, which was promoted following the administration of PD98059, may ultimately deplete the myoblast pool; therefore cells upregulate the expression of Id3 mRNA as a negative regulatory mechanism to slow down the rate of differentiation.

Indeed, studies by Navarro et al. (2001) have suggested that IGF causes upregulation of Id2; therefore in our model, Id3 may be increased as a consequence of increased IGF-II expression as a mechanism of controlling the rate of differentiation in a feed-forward loop. In addition, utilising the non-differentiating myoblast cell line NFB4, Sarbassov et al. has shown that myogenin and IGF-II are capable of activating each other's expression. Together, these studies suggest crosstalk between IGF system and both positive and negative regulators of differentiation. Given our MRF data, we therefore also wished to assess whether PD98059 influenced the expression of IGF system components in our model (Sarbassov et al. 1995). In order to provide additional lines of evidence for the proposed role of PD98059 in C2 myoblast differentiation, we examined changes in mRNA expression patterns of IGF-II and its receptor, which are upregulated in C2 cells and other myoblast lines to facilitate their differentiation (Tollefsen et al. 1989, Rosenthal et al. 1991, Stewart \& Rotwein 1996). Moreover, IGF-II and its receptor are produced in fusion differentiating skeletal muscle cells, suggesting that IGF-II may be an autocrine differentiation factor for muscle (Tollefsen et al. 1989). Consistent with the findings described above, the expression levels of IGF-II and IGF-IIR mRNAs were induced in all treatments, including PD98059, which had a profound impact particularly on IGF-II expression. This responsiveness of IGF-II to PD treatment may therefore indeed underpin the increased expression levels of the MRFs. Finally, in agreement with several studies which reported that IGFBP-5 is upregulated during the differentiation of several cell lines including myoblast cell lines (James et al. 1993, Cobb et al. 2004), and that IGFBP-5 is upregulated in response to MyoD (Bergstrom et al. 2002), our real-time PCR data also showed increased expression levels of IGFBP-5 mRNA, which were accompanied by cell differentiation regardless of the cell treatments, importantly, again linking the IGF system to the MRFs. Further studies are, however, needed to confirm this potential link between PD98059, IGF-II and MRFs.

Finally, we investigated the mechanism by which the PD may induce myoblast differentiation and the involvement of p38 MAPK in this process. The phosphorylation levels of p38 protein were significantly increased in PD-treated cells when compared with baseline control levels. These findings support previously proposed contribution of p38 MAPK in cell differentiation (Matsumoto et al. 2000, Hotokezaka et al. 2002, Lee et al. 2002). Additional possible mechanisms may contribute to this novel effect of PD98059 on myoblast differentiation that the PD98059 inhibitor may affect other unknown effector molecules or pathways, culminating in altered IGF-I and MRF expression, which underpin the enhanced differentiation reported.

Taken together, our data suggest that the chemical inhibitor PD98059 could extensively enhance and accelerate myoblast differentiation through the activation of p38 MAPK. These findings uncover an important 'side effect' of PD98059 following a single dose, which was studied for $48 \mathrm{~h}$. The data suggest that PD98059 may function to enhance regulators of differentiation and ultimately myotube production, and thus reveals an important tool for dissecting the precise mechanisms underpinning this process.

\section{Declaration of Interest}

The authors declare that there is no conflict of interest that would prejudice the impartiality of this scientific work.

\section{Funding}

Funding for these studies was provided by the Institute for Biomedical Research into Human Movement and Health (IRM).

\section{References}

Alessi DR, Cuenda A, Cohen P, Dudley DT \& Saltiel AR 1995 PD 098059 is a specific inhibitor of the activation of mitogen-activated protein kinase kinase in vitro and in vivo. Journal of Biological Chemistry 270 27489-27494.

Andres V \& Walsh K 1996 Myogenin expression, cell cycle withdrawal, and phenotypic differentiation are temporally separable events that precede cell fusion upon myogenesis. Journal of Cell Biology 132 657-666.

Arnold HH \& Winter B 1998 Muscle differentiation: more complexity to the network of myogenic regulators. Current Opinion in Genetics and Development 8 539-544.

Atherton GT, Travers H, Deed R \& Norton JD 1996 Regulation of cell differentiation in C2C12 myoblasts by the Id3 helix-loop-helix protein. Cell Growth and Differentiation 7 1059-1066.

Bergstrom DA, Penn BH, Strand A, Perry RL, Rudnicki MA \& Tapscott SJ 2002 Promoter-specific regulation of MyoD binding and signal transduction cooperate to pattern gene expression. Molecular Cell 9 587-600. 
Buckingham M 1992 Making muscle in mammals. Trends in Genetics 8 144-148.

Cobb LJ, Salih DA, Gonzalez I, Tripathi G, Carter EJ, Lovett F, Holding C \& Pell JM 2004 Partitioning of IGFBP-5 actions in myogenesis: IGFindependent anti-apoptotic function. Journal of Cell Science 117 1737-1746.

Coolican SA, Samuel DS, Ewton DZ, McWade FJ \& Florini JR 1997 The mitogenic and myogenic actions of insulin-like growth factors utilize distinct signaling pathways. Journal of Biological Chemistry 272 6653-6662.

Davies SP, Reddy H, Caivano M \& Cohen P 2000 Specificity and mechanism of action of some commonly used protein kinase inhibitors. Biochemical Journal 351 95-105.

Edmondson DG \& Olson EN 1993 Helix-loop-helix proteins as regulators of muscle-specific transcription. Journal of Biological Chemistry 268 755-758.

Ewton DZ, Roof SL, Magri KA, McWade FJ \& Florini JR 1994 IGF-II is more active than IGF-I in stimulating L6A1 myogenesis: greater mitogenic actions of IGF-I delay differentiation. Journal of Cellular Physiology $16 \mathbf{1}$ $277-284$.

Favata MF, Horiuchi KY, Manos EJ, Daulerio AJ, Stradley DA, Feeser WS, Van Dyk DE, Pitts WJ, Earl RA, Hobbs F et al. 1998 Identification of a novel inhibitor of mitogen-activated protein kinase kinase. Journal of Biological Chemistry 273 18623-18632.

Florini JR, Ewton DZ \& Coolican SA 1996 Growth hormone and the insulin-like growth factor system in myogenesis. Endocrine Reviews $\mathbf{1 7}$ 481-517.

Foulstone EJ, Meadows KA, Holly JM \& Stewart CE 2001 Insulin-like growth factors (IGF-I and IGF-II) inhibit C2 skeletal myoblast differentiation and enhance TNF alpha-induced apoptosis. Journal of Cellular Physiology 189 207-215.

Galvin CD, Hardiman O \& Nolan CM 2003 IGF-1 receptor mediates differentiation of primary cultures of mouse skeletal myoblasts. Molecular and Cellular Endocrinology 200 19-29.

Halevy O, Novitch BG, Spicer DB, Skapek SX, Rhee J, Hannon GJ, Beach D \& Lassar AB 1995 Correlation of terminal cell cycle arrest of skeletal muscle with induction of p21 by MyoD. Science 267 1018-1021.

Hoshino R, Tanimura S, Watanabe K, Kataoka T \& Kohno M 2001 Blockade of the extracellular signal-regulated kinase pathway induces marked G1 cell cycle arrest and apoptosis in tumor cells in which the pathway is constitutively activated: up-regulation of p27(Kip1). Journal of Biological Chemistry 276 2686-2692.

Hotokezaka H, Sakai E, Kanaoka K, Saito K, Matsuo K, Kitaura H, Yoshida N \& Nakayama K 2002 U0126 and PD98059, specific inhibitors of MEK, accelerate differentiation of RAW264.7 cells into osteoclast-like cells. Journal of Biological Chemistry 277 47366-47372.

Isobe A, Hirayama E \& Kim J 1998 Characterization of myogenin expression in myotubes derived from quail myoblasts transformed with a temperature sensitive mutant of Rous sarcoma virus. Cell Structure and Function 23 57-67.

James PL, Jones SB, Busby WH Jr, Clemmons DR \& Rotwein P 1993 A highly conserved insulin-like growth factor-binding protein (IGFBP-5) is expressed during myoblast differentiation. Journal of Biological Chemistry 268 22305-22312.

Johnson GL \& Lapadat R 2002 Mitogen-activated protein kinase pathways mediated by ERK, JNK, and p38 protein kinases. Science $\mathbf{2 9 8}$ 1911-1912.

Koyama M, Matsuzaki Y, Yogosawa S, Hitomi T, Kawanaka M \& Sakai T 2007 ZD1839 induces p15INK4b and causes G1 arrest by inhibiting the mitogen-activated protein kinase/extracellular signal-regulated kinase pathway. Molecular Cancer Therapentics 6 1579-1587.

Krutzik PO \& Nolan GP 2003 Intracellular phospho-protein staining techniques for flow cytometry: monitoring single cell signaling events. Cytometry. Part A 55 61-70.

Kultz D, Madhany S \& Burg MB 1998 Hyperosmolality causes growth arrest of murine kidney cells. Induction of GADD 45 and GADD 153 by osmosensing via stress-activated protein kinase 2. Journal of Biological Chemistry 273 13645-13651.
Lee SE, Woo KM, Kim SY, Kim HM, Kwack K, Lee ZH \& Kim HH 2002 The phosphatidylinositol 3-kinase, p38, and extracellular signalregulated kinase pathways are involved in osteoclast differentiation. Bone $3071-77$.

Matsumoto M, Sudo T, Saito T, Osada H \& Tsujimoto M 2000 Involvement of p38 mitogen-activated protein kinase signaling pathway in osteoclastogenesis mediated by receptor activator of NF-kappa B ligand (RANKL). Journal of Biological Chemistry 275 31155-31161.

Meadows KA, Holly JM \& Stewart CE 2000 Tumor necrosis factor-alphainduced apoptosis is associated with suppression of insulin-like growth factor binding protein-5 secretion in differentiating murine skeletal myoblasts. Journal of Cellular Physiology 183 330-337.

Melnikova IN \& Christy BA 1996 Muscle cell differentiation is inhibited by the helix-loop-helix protein Id3. Cell Growth and Differentiation 7 1067-1079.

Miller KJ, Thaloor D, Matteson S \& Pavlath GK 2000 Hepatocyte growth factor affects satellite cell activation and differentiation in regenerating skeletal muscle. American Journal of Physiology. Cell Physiology 278 C174-C181.

Molkentin JD \& Olson EN 1996 Defining the regulatory networks for muscle development. Current Opinion in Genetics and Development 6 445-453.

Moon DO, Park C, Heo MS, Park YM, Choi YH \& Kim GY 2007 PD98059 triggers G1 arrest and apoptosis in human leukemic U937 cells through downregulation of Akt signal pathway. International Immunopharmacology 7 $36-45$.

Navarro M, Valentinis B, Belletti B, Romano G, Reiss K \& Baserga R 2001 Regulation of Id2 gene expression by the type 1 IGF receptor and the insulin receptor substrate-1. Endocrinology 142 5149-5157.

Radonic A, Thulke S, Mackay IM, Landt O, Siegert W \& Nitsche A 2004 Guideline to reference gene selection for quantitative real-time PCR. Biochemical and Biophysical Research Communications 313 856-862.

Rawls A \& Olson EN 1997 MyoD meets its maker. Cell 89 5-8.

Rommel C, Clarke BA, Zimmermann S, Nunez L, Rossman R, Reid K, Moelling K, Yancopoulos GD \& Glass DJ 1999 Differentiation stagespecific inhibition of the Raf-MEK-ERK pathway by Akt. Science $\mathbf{2 8 6}$ 1738-1741.

Rosenthal SM, Brunetti A, Brown EJ, Mamula PW \& Goldfine ID 1991 Regulation of insulin-like growth factor (IGF) I receptor expression during muscle cell differentiation. Potential autocrine role of IGF-II. Journal of Clinical Investigation 87 1212-1219.

Sarbassov DD, Stefanova R, Grigoriev VG \& Peterson CA 1995 Role of insulin-like growth factors and myogenin in the altered program of proliferation and differentiation in the NFB4 mutant muscle cell line. PNAS 92 10874-10878.

de la Serna IL, Roy K, Carlson KA \& Imbalzano AN 2001 MyoD can induce cell cycle arrest but not muscle differentiation in the presence of dominant negative SWI/SNF chromatin remodeling enzymes. Journal of Biological Chemistry 276 41486-41491.

Singleton JR \& Feldman EL 2001 Insulin-like growth factor-I in muscle metabolism and myotherapies. Neurobiology of Disease 8 541-554.

Stewart CE \& Rotwein P 1996 Insulin-like growth factor-II is an autocrine survival factor for differentiating myoblasts. Journal of Biological Chemistry 271 11330-11338.

Stewart CE, Newcomb PV \& Holly JM 2004 Multifaceted roles of TNF- $\alpha$ in myoblast destruction: a multitude of signal transduction pathways. Journal of Cellular Physiology 198 237-247.

Tollefsen SE, Sadow JL \& Rotwein P 1989 Coordinate expression of insulinlike growth factor II and its receptor during muscle differentiation. PNAS 86 1543-1547.

Venuti JM \& Cserjesi P 1996 Molecular embryology of skeletal myogenesis. Current Topics in Developmental Biology 34 169-206.

Wei S, Wang MW, Teitelbaum SL \& Ross FP 2002 Interleukin-4 reversibly inhibits osteoclastogenesis via inhibition of NF-kappa B and mitogenactivated protein kinase signaling. Journal of Biological Chemistry 277 6622-6630.

Weintraub H 1993 The MyoD family and myogenesis: redundancy, networks, and thresholds. Cell 75 1241-1244. 
Wu J \& Lim RW 2005 Regulation of inhibitor of differentiation gene 3 (Id3) expression by Sp2-motif binding factor in myogenic $\mathrm{C} 2 \mathrm{C} 12$ cells: downregulation of DNA binding activity following skeletal muscle differentiation. Biochimica et Biophysica Acta 1731 13-22.

Wu Z, Woodring PJ, Bhakta KS, Tamura K, Wen F, Feramisco JR, Karin M, Wang JY \& Puri PL 2000 p38 and extracellular signal-regulated kinases regulate the myogenic program at multiple steps. Molecular and Cellular Biology 20 3951-3964.

Yaffe D \& Saxel O 1977 Serial passaging and differentiation of myogenic cells isolated from dystrophic mouse muscle. Nature $\mathbf{2 7 0}$ 725-727.

Yamaguchi K, Tomita H, Sugano E, Nakazawa T \& Tamai M 2002 Mitogenactivated protein kinase inhibitor, PD98059, inhibits rat retinal pigment epithelial cell replication by cell cycle arrest. Japanese Journal of Ophthalmology 46 634-639.
Zheng SM, Jiang MD, Zeng WZ, Xu H, Wang YX, Ma HD, Xie FW, Zhang Y, Qin JP \& Wu XL 2007 Effects of extracellular signal-regulated kinase on rat cultured hepatic stellate cells stimulated by acetaldehyde. Journal of Digestive Diseases 8 148-153.

Zhu W, Boachie-Adjei O, Rawlins BA, Frenkel B, Boskey AL, Ivashkiv LB \& Blobel CP 2007 A novel regulatory role for stromal-derived factor-1 signaling in bone morphogenic protein-2 osteogenic differentiation of mesenchymal C2C12 cells. Journal of Biological Chemistry 282 18676-18685.

Received in final form 28 April 2008

Accepted 8 May 2008

Made available online as an Accepted Preprint

8 May 2008 